\title{
ANTIOXIDANTS AND THEIR IMPORTANCE DURING MUSCULAR EXERCISE: A REVIEW
}

\author{
Ljiljana Bjelakovic $^{1}$, Gordana Kocić ${ }^{2}$, Dragan Radovanovic ${ }^{3}$, Vladimir Antic ${ }^{3}$, Bojko Bjelakovic ${ }^{4}$, Zorica Antic ${ }^{5}$ \\ ${ }^{1}$ Faculty of Sport and Physical Education, University of Niš, Serbia \\ ${ }^{2}$ Institute of Biochemistry, Faculty of Medicine, University of Niš, Serbia \\ ${ }^{3}$ Department of Medical Science, Faculty of Sport and Physical Education, University of Niš, Serbia \\ ${ }^{4}$ Pediatric Clinic, Faculty of Medicine, University of Niš, Serbia \\ ${ }^{5}$ Faculty of Medicine, University of Niš, Serbia
}

\begin{abstract}
Physiological levels of reactive oxygen species, as an essential part of the homeostatic milieu, are required for normal functioning of skeletal muscle. High levels of reactive oxygen species promote contractile dysfunction resulting in muscle weakness and fatigue, oxidative stress, apoptosis and necrosis of muscle cells. It is known that both resting and contracting skeletal muscles produce reactive oxygen species and reactive nitrogen species. The first suggestion that physical exercise results in free radical-mediated damage to tissues appeared in 1978. The newest researches investigate the mechanisms by which oxidants influence skeletal muscle contractile properties and explore how to protect muscle from oxidant-mediated dysfunction. Principal antioxidant enzymes include superoxide dismutase, glutathione peroxidase, and catalase. Numerous non-enzymatic antioxidants exist in cells within skeletal muscle fibers, the most abundant of which include glutathione, bilirubin, $\alpha$-Lipoic acid, uric acid, and ubiquinones, or coenzyme $Q(\mathrm{Co} Q)$ andflavonoids. Dietary antioxidants are vitamins $C$ - L ascorbic acid, vitamin A, retinol and their provitamins, carotenoids (especially $\beta$-carotene), vitamins E, tocopherol (especially $\alpha$-tocoferol ), folic acid or folates. The usage of endogenous enzymatic and non-enzymatic antioxidants protects muscle from strong damaging effects caused by free radicals during acute exercise or longer term physical exercise. Scientific researches now confirm that the long-term use of antioxidants is safe and effective. The actual recommendation for physically active individuals is to ingest a diet rich in antioxidants.
\end{abstract}

Key words: physical activity, human body, antioxidants, diet.

\section{Introduction}

Free radicals production is a normal process in the life of aerobic organisms. Reactive oxygen species (ROS) and reactive nitrogen species (RNS) are continuously produced during normal skeletal muscle metabolism $[1,2]$. Some of them have beneficial effects, notably as a part of the body's natural immune system [3].

Low and physiological levels of reactive oxygen species (ROS), such as superoxide, hydrogen peroxide, the hydroxyl radical and nitric oxide (NO) increase blood flow to skeletal muscle during physical exercise $[4,5]$.

Exercise was associated with an increased formation of free radicals, reactive oxygen species (ROS) and reactive nitrogen species (RNS) [6,7]. In young individuals, ROS are required for normal force production in skel-

*Correspondence to: Prof. Ljiljana Bjelaković, $\mathrm{MD}, \mathrm{PhD}$ Faculty of Sport and Physical Education, University of Niš, 10a Čarnojevića, 18000 Niš, Serbia

Phone: +38118510900

E-mail: 1jilja975@gmail.com

Received September $18^{\text {th }}, 2016$, accepted for publication January $16^{\text {th }}, 2017$ etal muscle, for the development of training-induced adaptations in endurance performance, as well as for the induction of the endogenous defense systems [8]. A greatly increased rate of free radical production, ROS and RNS, caused by exhaustive exercise, may exceed the capacity of the cellular defense system causing attack of free radicals on the cell membranes initiating the skeletal muscle damage and cause the oxidative stress, apoptosis and necrosis of the muscle cells [9-12].

The first suggestion that physical exercise results in free radical-mediated damage to tissues appeared in 1978 and after that there have appeared numerous data about exercise and oxidative stress [13]. Under physiological conditions, these deleterious species are mostly removed by the cellular antioxidant systems which include endogenous human body enzymic and non-enzymic antioxidants that work together to scavenge free radicals and who protect muscle function during physical exercise by maintaining an effective balance between free radical production and preventing potentially deleterious free radical effects. Antioxidant activity was determined by the ability of each compound to scavenge the long-lived free radicals [5,14-19]. 
Both enzymic and non-enzymic antioxidants exist in the intracellular and extracellular environments to detoxify ROS. These scavengers are located throughout the cell and provide protection against free radicals' toxicity using different approaches. Primary strategies include conversion of free radicals into less-active molecules (i.e. scavenging), and prevention of the transformation of lessreactive free radicals into more damaging forms (i.e. prevention of the transformation of $\mathrm{H}_{2} \mathrm{O}_{2}$ into the damaging hydroxyl radical) [14]. Maintenance of oxidative -antioxidant homeostasis is critical for the normal function and survival of all aerobic organisms because an imbalance between ROS and antioxidants is referred to as oxidative stress [2,19]. Intense and prolonged exercise can result in oxidative damage to both proteins and lipids in the contracting myocytes [20].

In general, slow-twitch, mitochondria-rich (type I) fibers have an increased content of protective systems compared with fast (type II) fibers [15,21].

\section{Enzymic and Non-enzymic Human Body Antioxidants}

During intense and exhaustive exercise cells continuously produce free radicals and reactive oxygen species (ROS) as part of metabolic processes in skeletal muscle. These free radicals are neutralized by the antioxidant defense system. These endogenous human body protective systems comprise enzymatic and non-enzymatic antioxidants.

\section{a) Primary antioxidant enzymes}

The group of primary antioxidant enzymes in human muscles comprises both mitochondrial and cytosolic isoforms of superoxide dismutase (EC 1.15.1.1; SOD), manganese containing SOD and cuprum, zinc-containing MnSOD and CuZnSOD, respectively, catalase (CAT) (EC 1.11.1.6) and glutathione peroxidase (GPX), (EC 1.11.1.9; [21]. These enzymes are responsible for removing superoxide radicals, $\mathrm{H}_{2} \mathrm{O}_{2}$ and organic hydroperoxides. Additional antioxidant enzymes such as thioredoxin, glutaredoxin, and peroxiredoxin reductase also contribute to cellular protection against oxidation $[13,18]$. An acute exercise or longer term exercise result in increased activities of superoxide dismutase, catalase or glutathione peroxidase in animal and human muscles [6,23-26].

\section{Superoxide dismutase (EC 1.15.1.1; SOD)}

Superoxide dismutase (SOD) forms the first line of defense against superoxide radicals in order to form hydrogen peroxide $\left(\mathrm{H}_{2} \mathrm{O}_{2}\right)$ and oxygen $\left(\mathrm{O}_{2}\right)$ :

$$
2 \mathrm{O}_{2}^{\bullet-}+2 \mathrm{H}^{+} \stackrel{\text { Superoxide dismutase }}{\longrightarrow} \mathrm{O}_{2}+\mathrm{H}_{2} \mathrm{O}_{2}
$$

Superoxide dismutase must work with enzymes that remove $\mathrm{H}_{2} \mathrm{O}_{2}$, that is with catalase. In mammals, three isoforms of SOD (SOD1, SOD2, SOD3) exist, and all require a redox active transition metal in the active site to accomplish the catalytic breakdown of the superoxide anion. The catalytically active metal can be copper, iron, manganese or nickel [27,28]. Exercise training significantly increased superoxide dismutase activity in the muscle soleus [29]. Mitochondrial SOD activity was increased by $37 \%$ in fast-twitch red and slow-twitch red types of muscle and $14 \%$ in white muscle [22].

Two of the SOD isoforms are located within cells, whereas the third SOD isoform is found in the extracellular space. Manganese (Mn) or copper/zinc $(\mathrm{Cu} / \mathrm{Zn})$-dependent superoxide dismutase (SOD), are located in the matrix and intermembrane space of mitochondria, and quickly dismutate the superoxide generated by mitochondria to $\mathrm{H}_{2} \mathrm{O}_{2}$ to prevent oxidative stress $[3,27,28,30]$.

The relative allocation of the $\mathrm{SOD}_{1}$ and $\mathrm{SOD}_{2}$ isoenzymes varies across tissues. In skeletal muscle, 15-35\% of the total SOD activity is in the mitochondria, and theremaining $65-85 \%$ are in the cytosol. SOD activity is highest in oxidative muscles that contain a high percentage of type I and type IIa fibers compared with muscles with low mitochondrial volumes. SOD activity in skeletal muscle is not constant and can be modified by activity Endurance exercise training promotes $20-112 \%$ increases in the activities of both SOD1 and SOD2 in the exercised [13].

\section{Glutathione peroxidase (EC 1.11.1.9; GPX)}

All glutathione peroxidases (GPX) enzymes catalyze the reduction of $\mathrm{H}_{2} \mathrm{O}_{2}$ or organic hydroperoxide ( $\left.\mathrm{ROOH}\right)$ to water $\left(\mathrm{H}_{2} \mathrm{O}\right)$ and alcohol $(\mathrm{ROH})$, using reduced glutathione $(\mathrm{GSH})$, or in some cases thioredoxin or glutaredoxin as the electron donors [13,31]. Glutathione peroxidase (GPx) removes $\mathrm{H}_{2} \mathrm{O}_{2}$ by coupling its reduction to water with oxidation of reduced glutathione $(\mathrm{GSH})$ :

$$
\mathrm{H}_{2} \mathrm{O}_{2}+2 \mathrm{GSH} \stackrel{\text { Glutathion peroxidase }}{\longrightarrow} \mathrm{GSSH}+2 \mathrm{H}_{2} \mathrm{O}
$$

Selenoproteome has five glutathione peroxidases in mammals (GPX1-GPX5) [20,31]. The highly oxidative fibers - type I, contain the highest GPX activity. The fact that many GPX isoenzymes will reduce a wide range of hydroperoxides ranging from $\mathrm{H}_{2} \mathrm{O}_{2}$ to complex organic hydroperoxides makes glutathione peroxidases (GPX) an important intracellular antioxidant to protect against ROS-mediated damage to membrane lipids, proteins, and nuclei acids. Glutathione peroxidases (GPX) increase in skeletal muscle fibers during regular and endurance exercise training along with increased cellular concentrations of glutathione in skeletal muscles, causing the risk reduction of cellular injury [3,13,14,31]. The reduction of GSSG back to GSH is done by glutathione reductase, a flavin containing enzyme, whereby NADPH provides the reducing power $[3,31]$. Skeletal muscles produce NADPH primarily via isocitrate dehydrogenase (ICD) through citric cycle but many tissues produce NADPH by glucose-6-phosphate dehydrogenase via the pentose pathway [1]. 


\section{Catalase (EC 1.11.1.6)}

Catalase (CAT) has principal biochemical functions to catalyze the break down of $\mathrm{H}_{2} \mathrm{O}_{2}$ into $\mathrm{H}_{2} \mathrm{O}$ and $\mathrm{O}_{2}$, i.e., 2 $\mathrm{H}_{2} \mathrm{O}_{2} \rightarrow 2 \quad \mathrm{H}_{2} \mathrm{O}+\mathrm{O}_{2}$. Catalase is widely distributed within the cell. Iron is a required cofactor attached to the active site of the enzyme. Catalase degrades $\mathrm{H}_{2} \mathrm{O}_{2}$ only when $\mathrm{H}_{2} \mathrm{O}_{2}$ reaches high concentrations [32,33]. Highly oxidative muscle fibers have the highest CAT protein levels and fibers with low oxidative capacity have the lowest enzyme activity [3,13].

The depleted activity levels of superoxide dismutase, catalase, glutathione peroxidase in the exercise animals indicated decreased antioxidative defense system in the muscle [26].

\section{Accessory antioxidant enzymes}

In addition to the primary antioxidant enzymes, cells contain the thioredoxin, glutaredoxin, and peroxiredoxin, the enzymes systems that directly or indirectly participate in the maintenance of redox balance [33].

The thioredoxin antioxidant system is composed of thioredoxin (TRX) and thioredoxin reductase [34-36]. TRX is the major ubiquitous disulfide reductase responsible for maintaining proteins in their reduced state. Oxidized TRX is then reduced by electrons from NADPH via thioredoxin reductase. Selenium (Se) is essential for the activity of thioredoxin reductase, explaining why this trace element is required for cell proliferation [34,37].

Glutaredoxin (GRX), similar to TRX, is a thiodisulfide oxidoreductase that is involved in the protection and repair of protein and non-protein thiols during periods of oxidative stress. GRX protects thiols by the transfer of electrons from NADPH to disulfide substrates, and this catalytic cycle is coupled with glutathione and glutathione reductase $[34,37,38]$. Human cells contain three different GRXs; GRX1 is located in cytosol, whereas both GRX2 and GRX5 are located in the mitochondria.

Peroxiredoxin (PRX) was discovered in 1988 and is a novel peroxidase capable of reducing both hydroperoxides and peroxynitrate with the use of electrons provided by a physiological thiol like TRX. Although peroxiredoxin (PRXs) may defend against cellular oxidative stress, the importance of their antioxidant role in mammalian cells remains unclear [36].

The effects of regular exercise on the TRX, GRX, and PRX systems in skeletal muscles remain unknown. Exercise-induced changes in one or all of these antioxidant systems could contribute to the redox adaptation to exercise $[35,36,39]$.

\section{Non-enzymic Antioxidants and Dietary Compounds}

\section{b) Vitamins (phytonutrients) as antioxidants}

Vitamins are organic compounds required by humans in small amounts from the diet.

The group of dietary antioxidants, dietary phytonutrient, vitamins, include vitamins $\mathrm{C}$ - $\mathrm{L}$ ascorbic acid, vitamin $\mathrm{A}$, retinol and their provitamins, carotenoids (especially $\beta$ - carotene), vitamins E, tocopherol (especially $\alpha$-tocopherol), folic acid or folates. In humans, vitamins function as metabolic regulators in small amounts from the diet, influencing a number of physiological processes important for exercise or sport performance. Many of the B-complex vitamins are involved in processing carbohydrate and fats for energy production, an important consideration during exercise of varying intensity. Several B vitamins, phyridoxal phosphate and vit. B2 (riboflavin, lactoflavin) are also essential for biosynthesis of hemoglobin in red blood cells, and for oxygen delivery to the muscles during aerobic endurance exercise [21].

It may be concluded that physically-active individuals might benefit from supplementation of vitamins [3].

\section{Vitamin C (L-ascorbic acid)}

Vitamin $\mathrm{C}$ has a main biological role as a reducing agent. Ascorbic acid is required for the hydroxylation of amino acids lysine and praline in protocollagen in the body. Without this hydroxylation protocollagen cannot properly cross-link into normal collagen fibrils. Thus, vitamin $\mathrm{C}$ is obviously important for maintenance of normal connective tissue. Vitamin $\mathrm{C}$ is also necessary for bone formation, since bone tissue has an organic matrix containing collagen as well as inorganic calcified portion. Collagen is a component of the ground substance surrounding capillary walls [40].

Various studies have demonstrated beneficial physiological effects of vitamin $\mathrm{C}$ supplementation in physically-active people. At physiological $\mathrm{pH}$ ascorbic acid exists as the ascorbate anion which is widely distributed in mammalian tissues. Vitamin $\mathrm{C}$ (L-ascorbic acid) distributes in the aqueous phase of the muscle cells. The antioxidant roles of vitamin $\mathrm{C}$ are numerous. Vitamin $\mathrm{C}$ can directly scavenge superoxide, hydroxyl and lipid hydroperoxide radicals. It modulates the intracellular redox status through maintaining sulfhydryl compounds, including glutathione in their reduced state. Increasing the concentration of vitamin $\mathrm{C}$ might interfere with antioxidant systems lowering the level of reduced glutathione as well as the activities of glutathione metabolic enzymes related to glutathione metabolism, such as glutathione reductase, glutathione peroxidase, and glutathione-S-transferase [41]. Furthermore, vitamin $\mathrm{C}$ plays a key role in recycling vitamin $\mathrm{E}$. In this reaction native vitamin $\mathrm{C}$, L-ascorbate is converted to a dehydroascorbate radical. This radical can be reduced back to native vitamin $\mathrm{C}$ by glutathione (GSH) [3].

\section{Vitamin A (axeroftol, retinol)}

The family of lipid-soluble antioxidants includes vitamin A (axeroftol, retinol) and provitamins- carotenoids, including $\beta$-carotene, vitamin E, $\alpha$-tocopherol. Vitamin E, $\alpha$-tocopherol, belongs in a family of lipid-soluble vitamin. These molecules are hydrophobic lipid soluble antioxidants located primarily in cell membranes and their primary function is to protect muscle membranes against oxidation. Because of their cellular location and their radical scavenging capacity, carotenoids are efficient biological antioxidants against lipid peroxidation. 
The antioxidant activity of $\beta$-carotene, as a radical-scavenging antioxidant against lipid peroxidation, was much smaller than that of $\alpha$-tocopherol [42].

\section{Vitamin E-tocopherol}

Vitamin $\mathrm{E}$ is potent lipid-soluble antioxidant in cell membranes and other lipid components of the cell and therefore it is essential for human nutrition [43,44]. In nature, compounds with vitamin $\mathrm{E}$ activity include $\alpha$-, $\beta$-, $\gamma$-, g- and $\delta$-tocopherols (TCP) as well as $\alpha-, \beta-, \gamma-$ and $\delta$-tocotrienols (TCT) (44). The capacity of vitamin $\mathrm{E}$ to prevent oxidation of unsaturated fatty acids is its primary function in the body. Supplementation with tocotrienol-rich fractions (TRF) from palm oil, a potent antioxidant from the natural Vitamin E family, may help in the prevention or treatment of several diseases [45]. Studies have shown vitamin E supplementation as an efficient means of reducing exercise-induced muscle damage due to free radical formation [18].

Vitamin E is a particularly important antioxidant because of its capacity to convert superoxide and hydroxyl radicals to less-reactive forms. Vitamin $\mathrm{E}$ can also break lipid peroxidation chain reactions which occur during ROS-mediated damage to cell membranes. In addition to its direct antioxidant properties, evidence indicates that the beneficial effects of vitamin $\mathrm{E}$ in cells also comes from its ability to control gene expression of several proteins (46). Many studies in humans have demonstrated antioxidant protection by high-dose vitamin E supplementation [3,47-49]. The supplementation with both vitamins $\mathrm{E}$ and $\mathrm{C}$ only prevented increases in lipid peroxidation (43).

\section{Folic acid, folacin}

Folic acid, folacin, belongs in a group of water soluble vitamins. Before functioning as a $\mathrm{C}_{1}$ carrier, folic acid must be reduced within cells to tetrahydrofolate (THF also $\mathrm{H}_{4}$ folate) through the action of dihydrofolate reductase (DHFR), an NADPH-requiring enzyme [50-52]. Through participating in biosynthesis of S-adenosyl methionine (SAMe) folic acid has an important function in glutathione synthesis. SAMe is a precursor for the synthesis of cysteine and thus glutathione (Fig. 1). SAMe effectively increase intracellular glutathione concentration in patients with liver disease [53,54]. Folate, vitamin B6, and vitamin B12 are required for homocysteine metabolism (Figure 1) by serving as cofactors for methionine synthase (B12), cystathionine synthase (B6), and cystathionase (B6) and as a substrate (5-methyltetrahydrofolate) for methionine synthase [55]. Cellular antioxidant metabolisms are linked by methylation and the transsulfuration pathway, which converts Methionine- Homocysteine cycle to cysteine, the important component in glutathione synthesis [54,56].

In situations where antioxidant defenses are compromised or where ROS production is grossly excessive, ROS are mediators of contraction-induced damage to skeletal muscle, (53). Through participating in biosynthesis of S-adenosyl methionine (SAMe) folic acid has an important function in glutathione synthesis. SAMe is

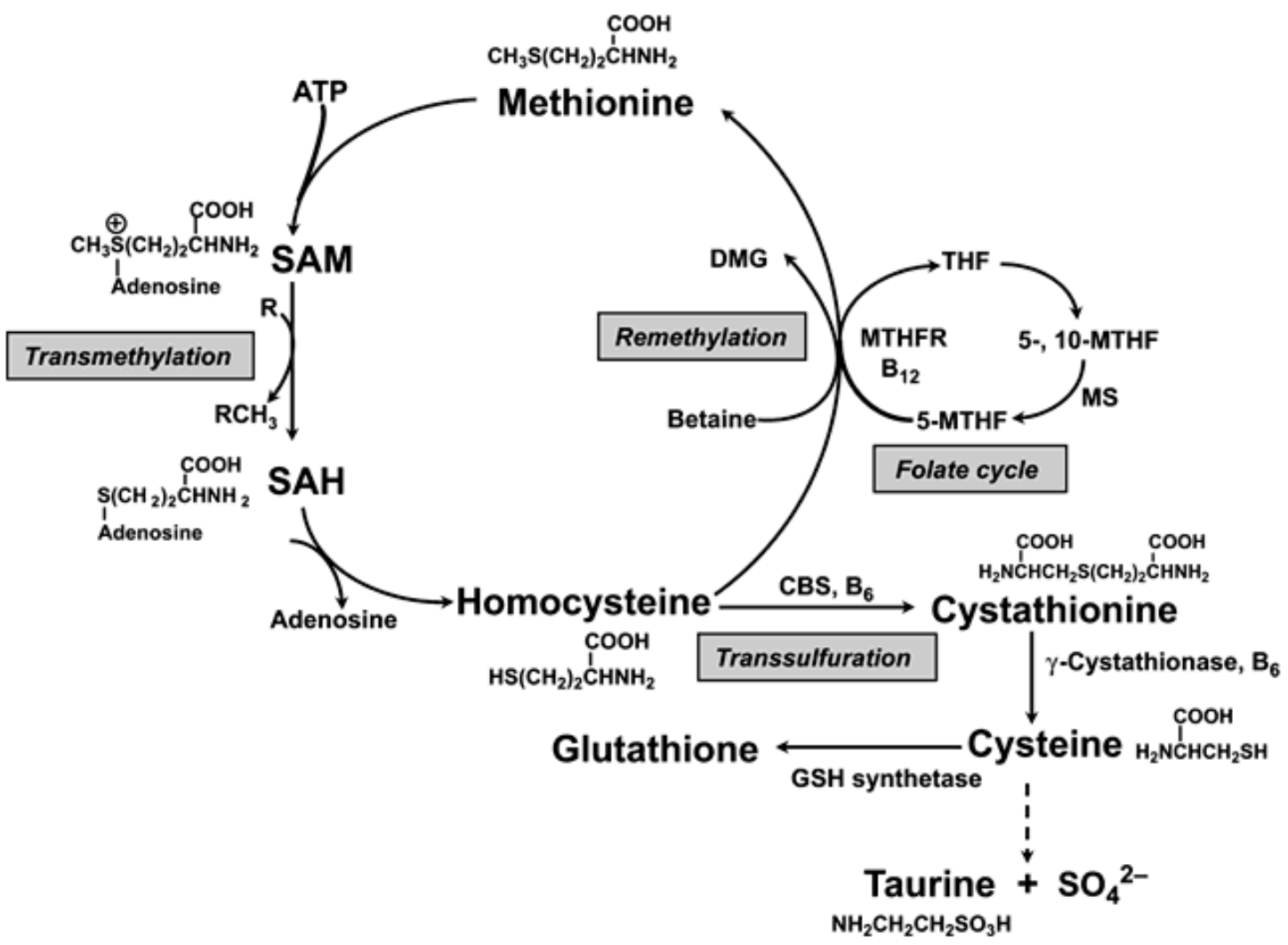

Fig 1 Folate (as THF), vitamin B6, and vitamin B12 are required for biosynthesis of Glutathione [54]. 
a precursor for the synthesis of cysteine and thus glutathione (Figure 1).

SAMe effectively increase intracellular glutathione concentration in patients with liver disease [53,54,57]. Literature data present conflicting results of vitamins' protective effects as antioxidant. However, despite the literature data, we could support that physically-active individuals might benefit from natural, human body constitutive, and diet rich in antioxidants [49].

\section{Human Body Non-enzymic Antioxidants and Dietary Compounds}

Beside several anti-oxidant enzyme systems and vitamins, cells contain endogenous non-enzymic anti-oxidants and naturally dietary compounds, to be used as scavenger free radicals molecules and to work against cellular damage [18].

The most important nonenzymatic antioxidants in muscle fibers include glutathione (GSH), bilirubin, $\alpha$ lipoic acid (LA), uric acid, ubiquinone or Coenzyme CoQ10.

The group of naturally dietary compounds, besides phytonutrients-vitamins, includes phytochemicals, flavonoids, chlorophylls, and others, present in most edible fruits and vegetables.

\section{c) Human body non-enzymic antioxidants}

\section{Glutathione}

Glutathione (GSH) is a tripeptide and is the most abundant nonprotein thiol in cells $[3,12,54,57,58]$. This antioxidant is primarily synthesized in the liver and transported to tissues via the circulation. GSH content varies across organs depending on their function $(3,58)$. The concentration of GSH found in skeletal muscle fibers varies across fiber types; for example, (slow) type I fibers contain 600\% higher GSH content (approximately 3mM) compared with (fast) type IIb fibers (3). As an antioxidant, GSH has multiple roles in cells. GSH can directly react with a variety of radicals by donating a hydrogen atom. Endogenous glutathione and thioredoxin, thiol antioxidants, are modulated with high oxygen consumption and ROS generation during physical exercise, controlling cellular function through redox-sensitive signaling and protein-protein interactions [59]. Exercise increased GSSG content and decreased GSH/GSSG in mitochondria. These data provided direct evidence that oxidant production in skeletal muscle is increased during prolonged exercise, with both mitochondrial respiratory chain and NADPH oxidase as potential sources [60-62]. GSH serves as a substrate for GPX to eliminate $\mathrm{H}_{2} \mathrm{O}_{2}$ and organic hydroperoxides. Furthermore, GSH is also involved in reducing other antioxidants in the cell including vitamins $\mathrm{C}$ and $\mathrm{E}$. Growing evidence indicates that exercise training results in an elevation in the activities of both superoxide dismutase and glutathione peroxidase along with increased cellular concentrations of glutathione in skeletal muscles. The exercise-induced increase in
GSH within muscle fibers is due to increased activity of a key enzyme involved in GSH synthesis, glutathione synthase ( $\gamma$-glutamylcysteine synthase), $[23,58,63]$.

Glutathione (GSH) and bilirubin are prominent endogenous antioxidant cytoprotectants. The water-soluble GSH primarily protects water soluble proteins, whereas the lipophilic bilirubin protects lipids from oxidation [64].

\section{Bilirubin}

Bilirubin is the final product of hemoprotein catabolism as heme oxygenase cleaves the heme ring to form biliverdin; biliverdin is then reduced by biliverdin reductase to form bilirubin. Exercise training significantly increased serum bilirubin levels [65]. Heme oxygenase (HO) has been shown to be important for attenuating the overall production of ROS [66,67].

Although both biliverdin and bilirubin are reducing species, bilirubin is considered to be the best physiological antioxidant cytoprotectant. Bilirubin, at micromolar concentrations in vitro, efficiently scavenges peroxyl radicals. Bilirubin is a potent antioxidant that can protect cells from a 10,000-fold excess of $\mathrm{H}_{2} \mathrm{O}_{2}$. The potent physiologic antioxidant actions of bilirubin reflect an amplification cycle whereby bilirubin, acting as an antioxidant, is itself oxidized to biliverdin and then recycled by biliverdin reductase back to bilirubin. This redox cycle may constitute the principal physiologic function of bilirubin [67-69]. Bilirubin possesses strong antioxidant potential against peroxyl radicals and has been shown to protect cells from toxic levels of hydrogen peroxide. It has been suggested that the powerful physiological antioxidant actions of bilirubin are a result of an amplification cycle whereby bilirubin acting as an antioxidant, is itself oxidized back to biliverdin and then recycled back to bilirubin via biliverdin reductase $[67,68]$. The data support the idea of a "beneficial" role for bilirubin as a physiological, chain-breaking antioxidant. Small amounts of plasma bilirubin are sufficient to prevent oxidation of albumin-bound fatty acids as well as of the protein itself. The data indicate a role for albumin-bound bilirubin (Alb-BR) as a physiological antioxidant in plasma and the extravascular space [70].

\section{3. a-Lipoic acid (LA)}

$\alpha$-Lipoic acid is a naturally occurring compound and can be obtained from the diet. It is concluded that alpha-lipoic acid supplementation diminishes oxidative damage. Studies suggest that LA also acts as a powerful micronutrient with diverse pharmacologic and antioxidant properties [4, 44]. As an antioxidant, LA directly terminates free radicals, chelates transition metal ions (e.g. iron and copper), increases cytosolic glutathione and vitamin $\mathrm{C}$ levels and prevents toxicities associated with their loss, $[71,72]$. $\alpha$-Lipoic acid (ALA), as lipoamide, is an endogenous intracellular thiol that acts as a cofactor in the multienzyme complexes that catalyze the oxidative decarboxylation of a-keto acids such as pyruvate, a- ketoglutarate, and branched chain $\alpha$ keto acids [73-75]. Their binding to an enzyme complex generally limits its function as an antioxidant. Normally, $\alpha-$ lipoic acid is present in very small quantities in tissues. 
ALA and DHLA couple has shown the ability to react with reactive nitrogen and oxygen species (RONS) such as hydroxyl radical, hypochlorous acid and singlet oxygen and reduce glutathione disulfide, tocopherol radicals and ascorbate [75].

Alfa-LA has been applied in sport as a dietary supplement. Alfa-LA supplementation attenuated exercise-induced oxidative damage in various tissues [76]. Alfa-LA can assist in the recycling of vitamin $\mathrm{C}$ and $\mathrm{E}[73,74,77]$. On the other hand, long-term Alfa-LA administration led to enhancement of lipid peroxidation [75].

\section{Uric acid}

Uric acid is a by-product of purine metabolism in humans and is potentially an important antioxidant in human biological fluids. Uric acid (UA) may function either as an antioxidant (primarily in plasma) or pro-oxidant (primarily within the cell). In the plasma, urate can prevent lipid peroxidation only as long as ascorbic acid is present [78]. At physiological $\mathrm{pH}$, almost all uric acid is converted to urate [79]. As an antioxidant, urate is able to protect against oxidative damage by acting as an electron donor. It appears that urate could be an antioxidant scavenger in skeletal muscle during exercise [79]. High UA concentrations are associated with increased serum antioxidant capacity and reduced oxidative stress during acute physical exercise in healthy subjects [80].

\section{Ubiquinones}

Ubiquinone, or coenzyme Q (CoQ), plays an important role in the production of chemical energy in the mitochondria. Coenzyme $\mathrm{Q}_{10}\left(\mathrm{CoQ}_{10}\right)$ is the major form of ubiquinone in human subjects. $\mathrm{CoQ}_{10}$ has gained considerable attention as an agent capable of influencing cellular bioenergetics and counteracting some of the damage caused by free radicals $[3,81]$. Humans can synthesize ubiquinones, hence, coenzyme $\mathrm{Q}_{10}$ cannot be considered a vitamin [82]. Coenzyme $\mathrm{Q}_{10}$ is soluble in lipids and is found in virtually all cell membranes, as well as lipoproteins; a cause that is essential in mitochondrial electron transport chain $[83,84]$. Reduced forms of ubiquinones, ubiquinols, are lipid-soluble and are efficient antioxidants, better antioxidants compared with ubiquinones [85]. Approximately $50 \%$ of the total cellular ubiquinone is located within the mitochondria, $30 \%$ in the nucleus, with the remaining $10 \%$ located in the endoplasmic reticulum and the cytoplasm. The presence of high concentrations of quinol in all membranes provides a basis for antioxidant action either by direct reaction with radicals or by regeneration of tocopherol and ascorbate [83].

$\mathrm{CoQ}_{10}$ is also a micronutrient. However, its bioavailability is limited compared to that of other lipidsoluble antioxidants like vitamin E. $\mathrm{CoQ}_{10}$ is the only lipidsoluble antioxidant synthesized endogenously. Ubiquinol inhibits the peroxidation of cell membrane lipids and also that of lipoprotein lipids present in the circulation [86].

Ubiquinone (Co Q10) is suitable for therapeutic use in the treatment of some muscular diseases [83,87]. It might therefore be used during strenuous exercise. Zuliani U et al. (1989) have evaluated the effect of pro- longed treatment with Co Q10 (100 mg/day per os for one month) on the biological changes induced by prolonged work on an ergometer bicycle in athletes; they observed any variation before or after the period of treatment with ubiquinone (Co Q10) [87].

Oxidative stress generated by physical exercise increases tissue ubiquinone levels by increasing biosynthesis in human body. Acute and chronic supplementation of $\mathrm{CoQ}_{10}$ may affect acute and/or chronic responses to various types of exercise $[85,88]$. $\mathrm{CoQ}_{10}$ supplementation increased total CoQ concentration in the slow-twitch muscles and was useful for reducing exhaustive exercise-induced muscular injury by enhancing stabilization of muscle cell membrane [89].

Coenzyme $\mathrm{Q}_{10}$ is available without prescription as a dietary supplement. Supplemental doses for adults range from $30-100 \mathrm{mg} /$ day, which is considerably higher than normal dietary coenzyme $\mathrm{Q}_{10}$ intake. Supplementation of healthy men with $120 \mathrm{mg} /$ day for three weeks did not increase skeletal muscle concentrations of coenzyme $\mathrm{Q}_{10}[90]$.

\section{d) Dietary compounds, phytochemicals}

The group of naturally dietary compounds includes phytochemicals such as flavonoid and chlorophylls and others present in most edible fruits and vegetables.

Phytochemicals are chemicals produced by plants that may affect health.

\section{Flavonoids}

Flavonoids are nearly ubiquitous in plants and are recognized as the pigments responsible for the colors of leaves, especially in last autumnal burst of hues and the many shades of yellow, orange, and red in flowers and food. The flavonoids are found in fruits, vegetables, nuts, seeds, herbs, spices, stems, flowers, as well as tea and red wine [91,92]. They are abundant in seeds, citrus fruits, olive oil, tea, and red wine. Flavonoids are polyphenols or polyhydroxylated phytochemicals. The two main classes of polyphenols include flavonoids and phenolic acids [81,91]. Flavonoids exert positive effects on human health; they are required for best activity, especially antioxidant and antiproliferative activity $[81,93]$. The mechanism of antioxidant activity of flavonoids can be characterized by direct scavenging or quenching of oxygen free radicals or excited oxygen species as well as inhibition of oxidative enzymes that generate these reactive oxygen species $[92,94]$. Some of them have been proposed to be beneficial in exercise and exercise performance. The wellknown flavonoids are quercetin, catechins, and resveratrol, and they have received great scientific attention. Quercetin supplementation increases mitochondrial biogenesis of exercise skeletal muscle $[81,96]$.

\section{Chlorophyll}

Chlorophyll is one of the main photosynthetic pigments, found in particularly large amounts in higher plants, dark green, leafy vegetables. Chlorophylls are important antioxidants found in foods. They give plants and algae 
their green color. Green, leafy vegetables collect light and energy by photosynthesis, and transform it into a powerful compound called chlorophyll. Sunlight and chlorophyll are our best friends $[1,44,96,97]$. The basic structure of chlorophyll is a porphyrin ring similar to that of heme in hemoglobin, although the central atom in chlorophyll is magnesium instead of iron. The long 20-carbon phytol tail attached to the porphyrin ring makes chlorophyll hydrophobic, fat-soluble and allows chlorophyll to incorporate into biological lipid membranes. Magnesium in chlorophyll contributes to muscle toning, contraction and relaxation. Chlorophyll $a$ and chlorophyll $b$ are natural, fat-soluble chlorophylls found in plants. The most important and widely present form in the plants is chlorophyll [44]. In these naturally occurring chlorophylls the functional group of $\mathrm{C} 7, \mathrm{a}-\mathrm{CH} 3$ or a $-\mathrm{CHO}$ group, define the $a$ and $b$ forms of chlorophyll, respectively. These naturally occurring $a$ and $b$ derivatives of chlorophyll are present in plants as breakdown products and as the products of chlorophyll digestion [1,44,97]. Chlorophyllin is a semi-synthetic mixture of sodium copper salts derived from chlorophyll. During the synthesis of chlorophyllin, the magnesium atom at the center of the ring is replaced with copper and the phytol tail is lost. Unlike natural chlorophyll, chlorophyllin is water-soluble [44, 97-101].

\section{References}

1. Lehninger AL, Nelson DL, Cox MM. Oxidative phophorylation and photophosphorylation. In: Nelson DL, Cox MM (ed) Principles of biochemistry, $4^{\text {th }}$ Ed., WH Freeman Co: New York, 2004; pp. 542-596

2. Powers SK, Ji LL, Kavazis AN, Jackson MJ. Reactive oxygen species: impact on skeletal muscle. Compr Physiol 2011; 1(2): 941-969.

3. Kanter M. Free radicals, exercise and antioxidant supplementation. mechanisms and impact on muscle force production. Proc Nutr Soc 1998; 57(1):9-13.

4. Smith MA, Reid MB. Redox modulation of contractile function in respiratory and limb skeletal muscle. Respir Physiol Neurobiol 2006; 151(2-3):229-241.

5. Radak Z, Zhao Z, Koltai E, Ohno H, Atalay M. Oxygen consumption dependent adaptive signaling. Antioxid Redox Signal 2013; 18(10):1208-1246.

6. McArdle A, Jackson MJ. Exercise, oxidative stress and ageing. Anat 2000; 197(Pt 4):539-541.

7. Pattwell DM, McArdle A, Morgan JE, Patridge TA, Jackson MJ. Release of reactive oxygen and nitrogen species from contracting skeletal muscle cells. Free Radic Biol Med 2004; 37:1064-1072.

8. Gomez-Cabrera MC, Ferrando B, Brioche T, Sanchis-Gomar F, Vina J. Exercise and antioxidant supplements in the elderly. J Sport Health Sci 2013; (2):94-100.

9. Davies KJ, Quintanilha AT, Brooks GA, Packer L. Free radicals and tissue damage produced by exercise. Biochem Biophys Res Commun 1982; 107:1198-1205.

10. Sjödin B, Hellsten Westing Y, Apple FS. Biochemical mechanisms for oxygen free radical formation during exercise. Sports Med 1990; 10(4):236-254.

11. Harris RA, Crabb DW. Metabolic interrelationships. In: Devlin TM (ed) Textbook of biochemistry with clinical correlations, fourth edition. A John Wiley \& Sons. Inc., Publication: New York, 1997: 525-562.

12. Hallwell B. The antioxidant paradox: less paradoxiocal now? Br J Clin Pharmacol 2013; 75(3):637-644.
Chlorophyll and his liquid derivatives are powerful antioxidants from the diet $[44,99]$. This antioxidant action can provide many of the benefits of eating vegetables and fruits that contain chlorophylls. As an antioxidants and health supplements chlorophylls prevent the formation of free radicals caused by oxidation of molecules and neutralize existing free radicals, making them harmless [97,101].

Most of benefits of liquid chlorophyll and their derivatives lack extensive research.

\section{Conclusion}

The present review tries to elucidate the mechanisms by which antioxidants influence the decreasing of toxic free radical effects on the skeletal muscle function in normal, physiological condition, and under intensive physical exercise. With this article we wish to clarify the normal acting of natural antioxidants, as a normal body constituent and compound of diet and to stimulate further research in this area.

Recent scientific data confirm that the long-term use of antioxidants is safe and effective. The actual recommendation for physically active individuals is to ingest a diet rich in antioxidants.

13. Powers SK, Jackson MJ. Exercise-induced oxidative stress: cellular mechanisms and impact on muscle force production. Physiol Rev 2008; 88:1243-1276

14. Powers SK, Lennon SL. Analysis of cellular responses to free radicals: focus on exercise and skeletal muscle. Proc Nutr Soc 1999; 58(4):1025-1033.

15. Jackson MJ, Pye D, Palomero J. The production of reactive oxygen and nitrogen species by skeletal muscle. J Appl Physiol 2007; 102(4):1664-1670.

16. Ji LL. Antioxidants and oxidative stress in exercise. Proc Soc Exp Biol Med 1999; 222(3):283-292.

17. Horton JW. Free radicals and lipid peroxidation mediated injury in burn trauma: the role of antioxidant therapy. Toxicology 2003; 189:75-88.

18. Bjørneboe A, Bjørneboe GE, Drevon CA. Absorption, transport and distribution of vitamin E. J Nutr 1990; 120(3):233-242.

19. Urso ML, Clarkson PM. Oxidative stress, exercise, antioxidant supplementation. Toxicology 2003; 189:41-54.

20. Powers SK, Talbert EE, Adhihetty PJ. Reactive oxygen and nitrogen species as intracellular signals in skeletal muscle. J Physiol 2011; 589(Pt 9):2129-2138.

21. Cortez-Toledo O, Schnair C, Sangngern P, Metzger D, Chao LC. Nur77 deletion impairs muscle growth during developmental myogenesis and muscle regeneration in mice. Berdeaux $\mathrm{R}$, editor. PLoS One [Internet]. 2017 Feb 7 [cited 2017 Feb 12];12(2): e0171268

22. Higuchi M, Cartier LJ, Chen M, Holloszy JO, Kanter MM. Superoxide dismutase and catalase in skeletal muscle: adaptive response to exercise. J Gerontol 1985; 40(3):281-286.

23. Ji LL. Exercise and oxidative stress: role of the cellular antioxidant systems. Exerc Sport Sci Rev 1995; 23:135-166.

24. Vina J, Gomez-Cabrera M-C, Lloret A, Marquez R, Minana JB, Pallardo FV, Sastre J. Free radicals in exhaustive physical exercise: mechanism of production, and protection by antioxidants. IUBMB Life 2000; 50:271-277.

25. Jacob RA. Trace elements. In: Tietz NW (ed) Textbook of clinical chemistry. W.B. Saunders: Philadelphia; 1986: 965-996. 
26. Borges L da S, Dermargos A, Junior EP da S, Weimann E, Lambertucci RH, Hatanaka E. Melatonin decreases muscular oxidative stress and inflammation induced by strenuous exercise and stimulates growth factor synthesis. J Pineal Res [Internet]. 2015 Mar [cited 2017 Feb 12];58(2):166-72.

27. Culotta VC, Yang M, O'Halloran TV. Activation of superoxide dismutases: Putting the metal to the pedal. Biochim Biophys Acta 2006; 1763(7):747-758.

28. Abreu IA, Cabelli DE. Superoxide dismutases-a review of the metal-associated mechanistic variations. Biochim Biophys Acta 2010; 1804(2):263-274.

29. Powers SK, Ji LL, Leeuwenburgh C. Exercise training-induced alterations in skeletal muscle antioxidant capacity: a brief review. Med Sci Sports and Exerc 1999; 31(7):987-997.

30. Hassan HM, Fridovich I. Chemistry and biochemistry of superoxide dismutases. Eur J Rheumatol Inflamm 1981; 4(2):160-172.

31. Arora S, Button DC, Basset FA, Behm DG. The effect of double versus single oscillating exercise devices on trunk and limb muscle activation. Int J Sports Phys Ther 2013; 8(4): 370-380.

32. Chance B, Sies H, Boveris A. Hydroperoxide metabolism in mammalian organs. Physiol Rev 1979; 59(3):527-605.

33. Moss DW, Henderson AR, Kachmar JF. Enzymes. In: Tietz NW (ed). The textbook of Clinical Chemistry. W. B. Saunders Company: Philadelphia, 1986:619-774.

34. Arnér ES, Holmgren A. Physiological functions of thioredoxin and thioredoxin reductase. Eur J Biochem. 2000; 267(20): $6102-6109$

35. Norberg J, Arner ES. Reactive oxygen species, antioxidants, and the mammalian thioredoxin system. Free Radic Biol Med 2001; 31(11):1287-1312.

36. Rhee SG, Woo HA, Kil IS, Bae SH. Peroxides and a regulator and sensor of local peroxiredoxin functions as a peroxidase. $\mathrm{J}$ Biol Chem 2012; 287:4403-4410.

37. Holmgren A. Antioxidant function of thioredoxin and glutaredoxin systems. Antioxid Redox Signal 2000; 2(4):811-820.

38. McCormick DK. Vitamins. Chapter 8B. In Tietz NW (ed), The textbook of Clinical Chemistry. W. B. Saunders Company: Philadelphia, 1986:927-964

39. Fujii J, Ikeda Y. Advances in our understanding of peroxiredoxin, a multifunctional, mammalian redox protein. Redox Report 2002; 7(3):1-8.

40. Englard S, Seifter S. The Biochemical Functions of Ascorbic Acid. Annu Rev Nutr [Internet]. 1986 Jul [cited 2017 Feb 12];6(1):365-406.

41. Sirmali R, Ginis Z, Sirmali M, Solac O, Şeliman B, Agackiran Y, Delibas N. Vitamin C as an antioxidant: evaluation of its role on pulmonary contusion experimental model. Turk J Med Sci 2014; 44:905-913.

42. Tsuchihashi H, Kigoshi M, Iwatsuki M, Niki E. Action of $\beta$ Carotene as an Antioxidant against Lipid Peroxidation. Archiv Biochem Biophys 1995; 323(1):137-147.

43. Traber MG. Relationship of vitamin $\mathrm{E}$ metabolism and oxidation in exercising human subjects. Br J Nutrition 2006; 96 (Suppl. 1):S34-S37.

44. Linus Pouling Institute, Oregon State University. Micronutrient Information Center. Lipoic acid; Chlorophyll and orophyllin. Copyright 2016.

45. Tan ML, Foong SC, Foong WC, Yusuff Y, Chettiar SM Tocotrienol-rich fractions (TRF) supplementation in schoolgoing children with Attention Deficit/Hyperactive Disorder (ADHD): a randomized controlled trial. BMC Nutrition 2016; 2(14):1-9.

46. Taridi NM, Yahaya MF, Teoh SL, Latiff AA, Ngah WZ, Das S, Mazlan. Tocotrienol rich fraction (TRF) supplementation protects against oxidative DNA damage and improves cognitive functions in Wistar rats. Clin Ter 2011; 162(2):93-98.

47. Warren JA, Jenkins RR, Packer L, Witt EH, Armstrong RB. Elevated muscle vitamin $\mathrm{E}$ does not attenuate eccentric exercise-induced muscle injury. J Appl Physiol (1985) 1992; 72(6):2168- 2175 .

48. Stepanyan V, Crowe M, Haleagrahara N, Bowden B. Effects of vitamin $\mathrm{E}$ supplementation on exercise-induced oxidative stress: a meta-analysis. Appl Physiol Nutr Metab 2014; 39(9):1029-1037.

49. Clarkson PM, Thompson HS. Antioxidants: what role do they play in physical activity and health? Am J Clin Nutr 2000; 72(suppl):637S-646S

50. Linus Pauling Institute, Oregon State University. Micronutrient Information Center. Folate. Copyright 2016.

51. Bailey LB, Gregory JF. Folate metabolism and requirements. J Nut 1999; 129:779-782.

52. King MW, $\mathrm{PhD} \mid$ (C) 1996-2016 themedicalbiochemistrypage. (2016): Vitamins and Minerals. org, LLC | info @ themedicalbiochemistrypage. org, Last updated August 11, 2016.

53. Jackson MJ. Reactive oxygen species and redox-regulation of skeletal muscle adaptations to exercise. Phil Trans R Soc B 2005; 360; 2285-2291.

54. Anstee QM, Day CP. S-adenosylmethionine (SAMe) therapy in liver disease: a review of current evidence and clinical utility. $\mathrm{J}$ Hepatol 2012; 57(5):1097-1099.

55. Fang Y-Z, Yang SH, Wu G. Free Radicals, antioxidants, and nutrition. Nutrition 2002; 18 (10):872-879.

56. Prudova A, Bauman Z, Braun A, Vitvitsky V, LuS C, Banerjee R. Sadenosylmethionine stabilizes cystathionine beta-synthase and modulates redox capacity. Proc Natl Acad Sci U S A 2006; 103 (17):6489-6494.

57. Wang SC, Frey PA. S-adenosylmethionine as an oxidant: the radical SAM superfamily. Trends Biochem Sci 2007; 32(3): 101-110.

58. Wu G, Fang Y-Z, Yang S, Lupton JR, Turner ND. Glutathione metabolism and its implications for health. J Nutr 2004; 134(3): 489-492.

59. Radak Z, Chung HY, Goto S. Systemic adaptation to oxidative challenge induced by regular exercise. Free Radic Biol Med 2008; 44:153-159.

60. Reid MB. Invited Review: Redox modulation of skeletal muscle contraction: what we know and what we don't. J Appl Physiol (1985) 2001; 90(2):724-731.

61. Reid MB, Durham WJ. Generation of reactive oxygen and nitrogen species in contracting skeletal muscle: potential impact on aging. Ann N Y Acad Sci 2002; 959:108-116.

62. Leeuwenburgh C, Fiebig R, Chandwaney R, Ji LL. Aging and exercise training in skeletal muscle: responses of glutathione and antioxidant enzyme systems. Am J Physiol 1994; 267: R439-R445.

63. Chen G, Chen Z, Hu Y, Huang P. Inhibition of Mitochondrial Respiration and Rapid Depletion of Mitochondrial Glutathione by $\beta$-Phenethyl Isothiocyanate: Mechanisms for Anti-Leukemia Activity. Antioxid Redox Signal [Internet]. 2011 Dec 15 [cited 2017 Feb 12];15(12):2911-21.

64. Sedlak TW, Saleh M, Higginson DS, Paul BD, Juluri KR, Snyder SH. Bilirubin and glutathione have complementary antioxidant and cytoprotective roles. Proc Natl Acad Sci U S A. 2009; 106(13):5171-5176.

65. Swift D, Johannsen NM, Earnest CP, Blair SN, Church TS. The effect of different doses of aerobic exercise training on total bilirubin levels. Med Sci Sports Exerc 2012; 44(4):569-574.

66. Abraham NG, Kappas A. Pharmacological and Clinical Aspects of Heme Oxygenase. Pharmacol Rev [Internet]. 2008 Mar 6 [cited 2017 Feb 12];60(1):79-127.

67. Jansen T, Daiber A. Direct antioxidant properties of bilirubin and biliverdin. Is there a role for biliverdin reductase? Front Pharmacol 2012; 3:30.

68. Ziberna L, Martelanc M, Franko M, Passamonti S. Bilirubin is an endogenous antioxidant in human vascular endothelial cells. Sci Rep 2016;6: 29240. DOI: 10. 1038/srep29240

69. Barañano D, Rao M, Ferris CD, Snyder SH. Biliverdin reductase: major physiologic cytoprotectant. Proc Natl Acad Sci U S A 2002; 99(25):16093-16098.

70. Stocker R, Glazer AN, Ames BN. Antioxidant activity of albumin-bound bilirubin. Proc Natl Acad Sci USA 1987; 84:5918-5922.

71. Smith AR, Shenvi SV, Widlansky M, Suh JH, Hagen TM. Lipoic acid as a potential therapy for chronic diseases associated with oxidative stress. Curr Med Chem 2004; 11(9):1135-1146. 
72. Tort F, Ferrer-Cortes X, Ribes A Differential diagnosis of lipoic acid synthesis defects J Inherit Metab Dis. 2016; 39(6):781-793. Epub 2016 Sep 1.

73. Packer L, Witt EH, Tritschler HJ. Alpha-Lipoic acid as a biological antioxidant. Free Radic Biol Med 1995; 19(2): 227-250.

74. Moini H, Packer L, Saris NE. Antioxidant and prooxidant activities of alpha-lipoic acid and dihydrolipoic acid. Toxicol Appl Pharmacol 2002; 182(1):84-90.

75. Zembron-Lacny A, Slowinska-Lisowska M, Szygula Z, Witkowski K, Stefaniak T, Dziubek W. Assessment of the antioxidant effectiveness of alpha-lipoic acid in healthy men exposed to muscle-damaging exercise. J Physiol Pharmacol 2009; 60(2): 139-143.

76. Petersen SK, Moreau RF, Smith EJ, Hagen TM. Is alpha-lipoic acid a scavenger of reactive oxygen species in vivo? Evidence for its initiation of stress signaling pathways that promote endogenous antioxidant capacity. IUBMB Life 2008; 60(6): 362-367.

77. Kagan VE, Shvedova A, Serbinova E, Khan S, Swanson C, Powell R, Packer L. Dihydrolipoic acid--a universal antioxidant both in the membrane and in the aqueous phase. Reduction of peroxyl, ascorbyl and chromanoxyl radicals. Biochem Pharmacol 1992; 44(8):1637-1649.

78. Sautin YY, Johnson RJ. Uric acid: the oxidant-antioxidant paradox. Nucleosides Nucleotides Nucleic Acids 2008; 27(6): 608-619.

79. deOliveira EP, Burini RC. High plasma uric acid concentration: causes and consequences. Diabetol Metab Syndr 2012; 4(12):1-7.

80. Waring WS, Convery A, Mishra V, Shenkin A, Webb DJ, Maxwell SR: Uric acid reduces exercise-induced oxidative stress in healthy adults. Clin Sci (Lond) 2003; 105(4):425-430.

81. Malaguti M, Angeloni C, Hrelia S. Polyphenols in exercise performance and prevention of exercise-induced muscle damage. Oxid Med Cell Longev 2013; 2013:825928. doi $10.1155 / 2013 / 825928$

82. Ernster L, Dallner G. Biochemical, physiological and medical aspects of ubiquinone function. Biochim Biophys Acta 1995; 1271(1):195-204.

83. Crane FL. Biochemical functions of coenzyme Q10. J Am Coll Nutr 2001; 20(6):591-598.

84. Molyneux S L, Young JM, Florkowski CM, Lever M, George PM. Coenzyme Q10: Is there a clinical role and a case for measurement? Clin Biochem Rev Vol 2008; 29:71-82.

85. Laaksonen R, Fogelholm M, Himberg JJ, Laakso J, Salorinne Y. Ubiquinone supplementation and exercise capacity in trained young and older men. Eur J Appl Physiol Occup Physiol 1995; 72(1-2):95-100

86. Littarru GP, Tiano LBioenergetic and antioxidant properties of coenzyme Q10: recent developments. Mol Biotechnol 2007; 37(1):31-37.
87. Zuliani U, Bonetti A, Campana M, Cerioli G, Solito F, Novarin A. The influence of ubiquinone (Co Q10) on the metabolic response to work. J Sports Med Phys Fitness 1989; 29(1):57-62.

88. Cooke M, Iosia M, Buford T, Shelmadine B, Hudson G Kerksick C, et al. Effects of acute and 14-day coenzyme Q10 supplementation on exercise performance in both trained and untrained individuals. J Int Soc Sports Nutr 2008; 4;5:8. doi: 10.1186/1550-2783-5-8.

89. Kon M, Kimura F, Akimoto T, Tanabe K, Murase Y, Ikemune S, Kono I. Effect of Coenzyme Q10 supplementation on exercise-induced muscular injury of rats. Exerc Immunol Rev 2007; 13:76-88.

90. Svensson M, Malm C, Tonkonogi M, Ekblom B, Sjodin B, Sahlin K. Effect of Q10 supplementation on tissue Q10 levels and adenine nucleotide catabolism during high-intensity exercise. Int J Sport Nutr 1999; 9(2):166-180.

91. Middleton E, Kandaswami C, Theoharid TC. The effects of plant flavonoids on mammalian cells: implications for inflammation, heart disease, and cancer. Pharmacol Rev 2000; 52 (4):673-751.

92. Pal D, Verma P. Flavonoids: a powerful and abundant source of antioxidants. Int J Pharm Pharm Sci 2013; 5(3):95-98.

93. Pietta PG. Flavonoids as antioxidants. J Nat Prod 2000; 63(7):1035-1042.

94. Terao J. Dietary flavonoids as antioxidants. Forum Nutr 2009 61:87-94.

95. Nieman DC, Williams AS, Shanely RA, Jin F, McAnulty SR, Triplett NT, Austin MD, Henson DA. Quercetin's influence on exercise performance and muscle mitochondrial biogenesis. Med Sci Sports Exerc 2010; 42(2):338-45.

96. Ferruzzi MG. Antioxidant and antimutagenic activity of dietary chlorophyll derivatives determined by radical scavenging and bacterial reverse mutagenesis assays. Food Sci 2006; 67(7): 2589-2595.

97. Hsu CY, Chao PY, Hu SP, Yang CM. The antioxidant and free radical scavenging activities of chlorophylls and pheophytins. Food Nutr Sci, 2013; 4:1-8.

98. Kamat JP, Boloor KK, Devasagayam TP. Chlorophyllin as an effective antioxidant against membrane damage in vitro and ex vivo. Biochim Biophys Acta 2000; 1487 (2-3):113-127.

99. Kumar SS, Shankar B, Sainis KB. Effect of chlorophyllin against oxidative stress in splenic lymphocytes in vitro and in vivo. Biochim Biophys Acta 2004 72(2):100-111.

100. Fahey JW, Stephenson KK, Dinkova-Kostova AT, Egner PA, Kensler TW, Talalay P. Chlorophyll, chlorophyllin and related tetrapyrroles are significant inducers of mammalian phase 2 cytoprotective genes. Carcinogenesis 2005; 26(7):1247-1255.

101. Hsu CY, Yang C M, Chen C M, Chao P Y, Hu S P. Effects of chlorophyll-related compounds on hydrogen peroxide induced DNA damage within human lymphocytes. J Agric Food Chem 2005; 53 (7):2746-50. 